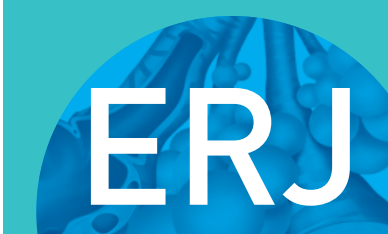

open research
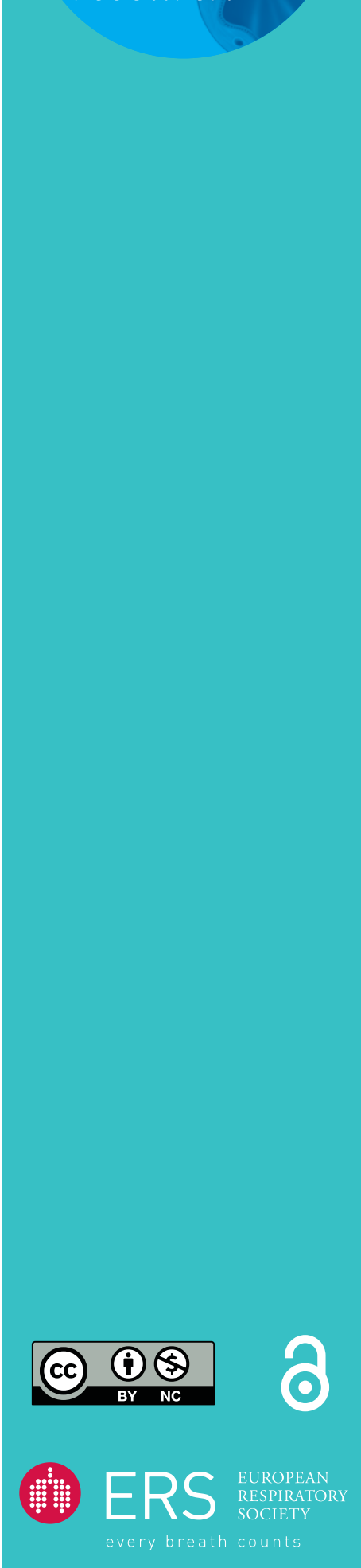

\section{Lung cancer in combined pulmonary fibrosis and emphysema: a large retrospective cohort analysis}

\author{
Faria Nasim and Teng Moua
}

Affiliation: Division of Pulmonary and Critical Care Medicine, Mayo Clinic, Rochester, MN, USA.

Correspondence: Teng Moua, Division of Pulmonary and Critical Care Medicine, Mayo Clinic, 200 First St SW, Rochester, MN 55905, USA. E-mail: moua.tengamayo.edu

\section{ABSTRACT}

Background: Combined pulmonary fibrosis and emphysema (CPFE) is characterised by upper lobe emphysema and lower lobe fibrosis. Our study aim was to determine the incident risk, presenting characteristics and outcome of lung cancer diagnoses in a cohort of CPFE patients over time.

Materials and methods: We conducted a retrospective cohort study assessing patients with radiological CPFE followed over a median of 76 months (range 1-237 months). Interval development of lung cancer and clinicopathological characteristics of those with and without lung cancer were compared and survival analysis performed.

Results: Lung cancer occurred in $26(11.6 \%)$ out of 230 CPFE patients, dominated by nonsmall cell lung cancer $(88 \%, n=23)$ with squamous cell carcinoma comprising the majority $(57 \%, n=13)$. There was a predominance of lower lobe (62\%) and subpleural (64\%) radiological presentation. Survival was reduced for the whole cohort by lung cancer even after adjusting for a priori covariables of age, sex, smoking packyears, presenting forced vital capacity and radiological honeycombing. Univariable predictors of increased mortality after lung cancer diagnosis included honeycombing (hazard ratio (HR) 3.03, 95\% CI 1.16-7.91; $\mathrm{p}=0.02$ ) and later stage presentation ( $\mathrm{HR} 4.77,95 \%$ CI 1.8-14.94; $\mathrm{p}=0.001$ ), with those able to undergo surgical resection having better survival (HR 0.29, 95\% CI 0.09-0.87; $\mathrm{p}=0.02$ ).

Conclusion: Lung cancer occurred in $26(11.6 \%)$ out of 230 CPFE patients and was dominated by squamous cell carcinoma presenting in a lower lobe peripheral distribution. Surgical resection appeared to improve survival in selected patients with earlier stage disease. Further studies are needed to develop a relevant screening programme for CPFE patients.

@ERSpublications

Lung cancer is common in CPFE patients followed over time, with possibly better survival in those diagnosed at earlier stages and successfully resected. Further studies to formulate diseasespecific cancer screening protocols are needed. https://bit.ly/3445Bxr

Cite this article as: Nasim F, Moua T. Lung cancer in combined pulmonary fibrosis and emphysema: a large retrospective cohort analysis. ERJ Open Res 2020; 6: 00521-2020 [https://doi.org/ 10.1183/23120541.00521-2020].

Received: 24 July 2020 | Accepted after revision: 9 Oct 2020

Copyright $\odot$ ERS 2020. This article is open access and distributed under the terms of the Creative Commons Attribution Non-Commercial Licence 4.0. 


\section{Introduction}

Combined pulmonary fibrosis and emphysema (CPFE) is a clinical entity characterised by a history of heavy smoking, pulmonary hypertension, hypoxaemia and relatively normalised spirometry and lung volumes in the context of severely impaired gas exchange [1]. Radiologically, CPFE presents as upper lobe predominant emphysema and lower lobe lung fibrosis [2]. Mortality is significant in CPFE with a median survival reported between 2.1 and 8.5 years and 5-year survival of 38-55\% [3]. CPFE has been recognised as an important risk factor for the development of lung cancer and appears to be associated with a generally worse prognosis $[4,5]$. Chronic lung injury with CPFE may influence the development and progression of lung cancer, perhaps related to the triple effects of smoking, emphysema and pulmonary fibrosis, all known factors associated with lung cancer development.

Although there have been descriptive studies, the association between newly diagnosed CPFE and lung cancer risk has not been well elucidated. The majority of prior studies began with diagnosed lung cancer cohorts [6-11], with the largest series to date comprising 4313 lung cancer patients from nine institutions reporting $265(6.1 \%)$ cases with associated CPFE [7]. Only three studies have reported the incidence of lung cancer in CPFE beginning with baseline CPFE prior to lung cancer diagnosis [5]. One study evaluated lung cancer risk in a series of 48 CPFE cases noting 12 (25\%) going on to develop lung cancer [4]. A second study found 22 (46.8\%) out of 47 CPFE patients with incident lung cancer [12], while a third and smaller study found six (20.6\%) out of 29 developing subsequent lung cancer [13]. A meta-analysis describing lung cancer in CPFE reported squamous cell carcinoma as the most common subtype (42.3\%), followed by adenocarcinoma (34.4\%) [5]. Lung cancer in CPFE patients appeared to exhibit advanced pathological staging with relatively short survival [7,9-14]. There is a single study to date reporting the location of presenting lung cancer lesions in CPFE [6]. The aim of our study was to report the frequency of incident lung cancer cases in a large retrospective cohort of CPFE patients (CPFE-LC) and describe presenting clinical features, management strategies and predictors of outcome.

\section{Materials and methods}

We conducted a retrospective cohort study of patients diagnosed with CPFE from January 1, 1995 to December 31, 2017, at Mayo Clinic (Rochester, MN, USA), a 1264-bed tertiary care centre. Institutional research review board approval was obtained (IRB 16-009700) and only patients providing informed consent for general study participation at the time of initial clinical visit were included. Data abstraction was performed by study investigators using a computerised query tool that allowed systematic search of clinical data stored in the enterprise data trust, using the terms "fibrosis" and "emphysema" in the descriptive notes of chest computed tomography (CT) scans $(n=256)$. Those without record of informed consent for de-identified cohort research were excluded $(n=12)$. All patients aged $>18$ years with radiologically confirmed CPFE were included for review. Clinically reported cases without available confirmatory CT imaging were excluded $(n=14)$. CT scans were read by expert radiologists at the time of diagnosis and reviewed by the authors to confirm radiological CPFE, defined as $\geqslant 10 \%$ of total involvement of both emphysema and lung fibrosis on imaging in any distribution. Fibrosis was defined as the presence of reticular or honeycomb change in any distribution, with or without traction bronchiectasis, and emphysema was defined as low attenuation areas without a parenchymal lining (cystic changes) either in a centrilobular or subpleural distribution, as defined by standard Fleischner criteria [14]. Further manual data abstraction from the electronic medical record was performed. Study variables included age at CPFE and lung cancer diagnosis, sex, reported presence of finger clubbing, smoker pack-years, pulmonary function testing (PFT), known causes of lung fibrosis, treatment of underlying lung disease, use of home oxygen, right ventricular systolic pressure (RVSP) on transthoracic echocardiogram (TTE) and interval diagnosis of lung cancer. Specific PFT parameters included percentage predicted total lung capacity (TLC), forced vital capacity (FVC), forced expiratory volume in $1 \mathrm{~s}\left(\mathrm{FEV}_{1}\right)$ and diffusing capacity of the lung for carbon monoxide $\left(D_{\mathrm{LCO}}\right)$. Summary PFT patterns were categorised as normal, obstructive, restrictive, mixed (obstruction and restriction), nonspecific (defined as isolated or proportionate decline in $\mathrm{FEV}_{1}$ and $\mathrm{FVC}$ with normal $\mathrm{FEV}_{1} / \mathrm{FVC}$ ratio and normal TLC) and isolated low $D_{\text {LCO. }}$ For patients diagnosed with lung cancer, additional variables were collected including histological subtype, lung cancer staging according to 2016 International Association for the Study of Lung Cancer criteria [15], broad treatment categories (chemotherapy with or without radiation versus surgical resection alone as adjunct), and survival and cause of death, if applicable or available. All lung cancer cases had pathology reports available for review as initially diagnosed by subspecialty pathologists at Mayo Clinic Rochester, in accordance with the 2004 World Health Organization international classification of lung and pleural tumours [16]. Timing of lung cancer diagnoses was defined as the date of clinician review for lung cancer or final pathology report. 


\section{Statistical analysis}

Statistical analysis was performed using JMP Software (version 13.0; SAS Institute, Cary, NC, USA). Data were presented as mean \pm SD or median (interquartile range (IQR)) for continuous variables and as counts and percentages for categorical variables. For comparison of baseline characteristics between those with and without lung cancer, Chi-squared or Fisher's exact test were used for categorical variables and one-way ANOVA for continuous variables. Follow-up for all-cause mortality was obtained in all cases and survival time was defined in months from the date of the first available chest CT with radiological CPFE (signifying a first date of CPFE diagnosis based on radiological definition) to the date of death or United States Social Security Death Index (USSDI) search date June 15, 2018, if still alive. All living and transplanted patients were censored from the date of USSDI search or date of transplant. Survival was compared between those with and without lung cancer diagnosis, using Kaplan-Meier and log rank, censored for live or transplanted patients. Cox proportional hazards regression was performed to determine predictors of death for the whole cohort with univariable analysis followed by multivariable adjustment of positive predictors $(\mathrm{p}<0.05)$ for a priori-selected covariables of age, sex, smoker pack-years, FVC percentage at presentation and presence of honeycombing, avoiding stepwise selection or spurious adjustments. Only univariable Cox regression analysis for predictors of survival after lung cancer diagnosis was performed for the CPFE-LC cohort, given the smaller sample size $(n=26)$. For the purposes of

TABLE 1 Baseline characteristics in combined pulmonary fibrosis and emphysema (CPFE) with and without lung cancer (LC) diagnosis

\begin{tabular}{|c|c|c|c|}
\hline & CPFE & CPFE-LC & p-value \\
\hline Patients & 204 & 26 & \\
\hline Age at diagnosis of CPFE years $(95 \% \mathrm{CI})$ & $68 \pm 9.1(67-70)$ & $66 \pm 7.1(63-69)$ & 0.18 \\
\hline Male & $155(76)$ & $18(69)$ & 0.45 \\
\hline Smoking status & & & 0.31 \\
\hline Active & $12(5.5)$ & 2 (8) & \\
\hline Former & 192 (94) & 24 (92) & \\
\hline Smoker pack-years $(95 \% \mathrm{CI})$ & $56 \pm 24.6(46-66)$ & $50 \pm 28.3(46-54)$ & 0.08 \\
\hline Finger clubbing & $40(20)$ & 7 (27) & 0.39 \\
\hline LABA use & 117 (57) & $11(42)$ & 0.15 \\
\hline Systemic steroid & 70 (34) & 10 (38) & 0.68 \\
\hline Immunosuppressive agents & 15 (7.4) & $1(4)$ & 0.51 \\
\hline Home oxygen & $155(76)$ & $16(62)$ & 0.11 \\
\hline RVSP mmHg & 49 (39-63) & $49(32-66.5)$ & 0.40 \\
\hline \multicolumn{4}{|l|}{ PFT findings } \\
\hline TLC \% pred $(95 \%$ CI) & $84.1 \pm 16.7(81-87)$ & $91.2 \pm 16.1(82-100)$ & 0.12 \\
\hline FVC \% pred $(95 \% \mathrm{CI})$ & $80.8 \pm 18.5(78-84)$ & $85.8 \pm 18.2(78-94)$ & 0.22 \\
\hline $\mathrm{FEV}_{1} \%$ pred $(95 \% \mathrm{CI})$ & $75.8 \pm 18.9(73-79)$ & $76.7 \pm 16.3(70-84)$ & 0.83 \\
\hline $\mathrm{FEV}_{1} / \mathrm{FVC}(95 \% \mathrm{CI})$ & $73.5 \pm 11.5(72-75)$ & $71 \pm 12.3(66-76)$ & 0.31 \\
\hline$D_{\text {Lco }} \%$ pred $(95 \% \mathrm{Cl})$ & $42.9 \pm 16.9(40-45)$ & $49.6 \pm 16.9(42-58)$ & 0.09 \\
\hline PFT pattern ${ }^{\#}$ & & & 0.86 \\
\hline Normal & $9(4)$ & $1(4)$ & \\
\hline Obstructive & $46(23)$ & $7(30)$ & \\
\hline Restrictive & $63(31)$ & $5(22)$ & \\
\hline Isolated low $D_{\text {Lco }}$ & $60(29)$ & $6(26)$ & \\
\hline Nonspecific & $9(4)$ & $3(13)$ & \\
\hline Mixed & $1(0.5)$ & $1(4)$ & \\
\hline \multicolumn{4}{|l|}{ Radiological features } \\
\hline Presence of honeycombing & $74(36)$ & 9 (35) & 1.0 \\
\hline Distribution of emphysema & & & 0.90 \\
\hline Centrilobular & $81(40)$ & 9 (35) & \\
\hline Subpleural & $32(16)$ & $3(12)$ & \\
\hline Mixed & $91(45)$ & $8(31)$ & \\
\hline Lung transplantation & $8(4)$ & $0(0)$ & 0.88 \\
\hline All-cause mortality & $103(50)$ & $21(81)$ & 0.003 \\
\hline \multicolumn{4}{|c|}{$\begin{array}{l}\text { Data are presented as } n \text {, mean } \pm S D, n(\%) \text { or median linterquartile range), unless otherwise stated. Bold } \\
\text { type represents statistical significance. LABA: long-acting } \beta_{2} \text {-agonist; RVSP: right ventricular systolic } \\
\text { pressure; PFT: pulmonary function test; TLC: total lung capacity; FVC: forced vital capacity; FEV }{ }_{1} \text { forced } \\
\text { expiratory volume in } 1 \mathrm{~s} \text {; } D_{\text {LCO }} \text { : diffusing capacity of the lung for carbon monoxide. \#: CPFE } n=188 \text {, } \\
\text { CPFE-LC } n=23 \text {. }\end{array}$} \\
\hline
\end{tabular}


modelling predictors, missing data for selected continuous variables was imputed with multivariate normal imputation using least-squares prediction and shrinkage from nonmissing variables (done specifically for smoker pack-years, RVSP, FVC, $\mathrm{FEV}_{1}$ and $D_{\mathrm{LCO}}$ ). Two-sided p-values $<0.05$ were considered statistically significant.

\section{Results}

230 patients with radiologically defined CPFE and clinical follow-up were reviewed for interval development of lung cancer. Median follow-up for the whole cohort was 75.6 months (95\% CI 60-103 months) from the date of radiological CPFE diagnosis to date of death, transplant or last known alive (USSDI search June 15, 2018). Lung cancer was diagnosed in 26 (11.6\%) patients over the observation period. Baseline demographic and clinical findings for CPFE-LC and non-lung cancer patients are presented in table 1 . There were no presenting differences between those with and without lung cancer except for greater overall percentage mortality in those with subsequent lung cancer diagnosis $(50 \%$ versus $81 \%, \mathrm{p}=0.003)$. In addition, there were more males in the cohort overall $(\mathrm{n}=173,75 \%)$ and all were active or former smokers. Pack-years of smoking were similar between those with and without lung cancer (50 versus 56, $\mathrm{p}=0.08$ ). Presence of finger clubbing was $20 \%$ and $27 \%$, respectively, for each cohort along with similar use of directed therapy for CPFE and home oxygen. RVSP as seen on TTE was elevated similarly (median $49 \mathrm{mmHg}$ (IQR 39-63 mmHg) versus $49 \mathrm{mmHg}$ (IQR 32-66.5 mmHg). PFT findings were also comparable by individual parameters as well as final summary pattern, with nearly equivalent

TABLE 2 Combined pulmonary fibrosis and emphysema (CPFE) lung cancer characteristics

\begin{tabular}{|c|c|}
\hline \multicolumn{2}{|l|}{ Histology } \\
\hline NSCLC/small cell carcinoma & $23 / 3(88 / 12)$ \\
\hline Adenocarcinoma & 8 (35) \\
\hline Squamous cell & $13(57)$ \\
\hline Large cell & $1(4)$ \\
\hline Other & $1(4)$ \\
\hline \multicolumn{2}{|l|}{ Clinical staging } \\
\hline \multicolumn{2}{|l|}{ NSCLC } \\
\hline Stage I & $5(21.7)$ \\
\hline Stage II & $5(17.4)$ \\
\hline Stage IIIA & $3(17.4)$ \\
\hline Stage IIIB & $1(4.3)$ \\
\hline Stage IV & 9 (39) \\
\hline \multicolumn{2}{|l|}{ Small cell lung cancer } \\
\hline Limited disease & $3(100)$ \\
\hline \multicolumn{2}{|l|}{ Location } \\
\hline Left/right & $12 / 11(52 / 48)$ \\
\hline Left lower lobe & $8(31)$ \\
\hline Right lower lobe & $8(31)$ \\
\hline Left upper lobe & $3(12)$ \\
\hline Right upper lobe & $3(12)$ \\
\hline Other (right middle lobe, lingula, hilar only) & $4(15)$ \\
\hline Located within $2 \mathrm{~cm}$ of pleural edge & $16(64)$ \\
\hline \multicolumn{2}{|l|}{ Treatment } \\
\hline No therapy (direct hospice or palliation) & $4(15)$ \\
\hline Chemotherapy alone & $1(4)$ \\
\hline Radiation alone (including SBRT) & $7(27)$ \\
\hline Chemotherapy and radiation & $6(23)$ \\
\hline Surgical resection alone & $6(23)$ \\
\hline Surgical resection+chemotherapy or radiation & $2(8)$ \\
\hline Deaths & $21(81)$ \\
\hline \multicolumn{2}{|l|}{ Cause of death } \\
\hline Primary cancer & 12 (55) \\
\hline Infection & $3(15)$ \\
\hline Acute exacerbation of ILD & $1(5)$ \\
\hline Unrelated to CPFE and/or lung cancer & $2(10)$ \\
\hline Unknown & $3(15)$ \\
\hline
\end{tabular}

Data are presented as $\mathrm{n}(\%)$. $\mathrm{n}=26$. NSCLC: nonsmall cell lung cancer; SBRT: stereotactic body radiotherapy; ILD: interstitial lung disease. 
distributions of obstructive, restrictive and isolated $D_{\text {LCO }}$ findings $(\mathrm{p}=0.86)$. Secondary causes of interstitial lung disease were found in 42 cases, comprising 40 cases of autoimmune or connective-tissue disease and two cases of biopsy-proven desquamative interstitial pneumonia. All secondary cases were clinically diagnosed by multidisciplinary team discussion involving rheumatology and/or pathology team members at the time of diagnosis.

Cancer characteristics at the time of diagnosis for CPFE-LC patients are presented in table 2. Nonsmall cell lung cancer was more common $(n=23,88 \%)$, with a predominance of squamous cell carcinoma in $57 \%$ of cases, followed by adenocarcinoma $(n=8,35 \%)$ and large cell carcinoma $(n=1,4 \%)$. Three cases of small cell lung cancer were noted (all presenting with limited staging), with one patient having both small cell and adenocarcinoma. Another patient had both MALToma (mucosa-associated lymphoid tissue) and adenocarcinoma. At the time of diagnosis, 13 (56.6\%) cases were potentially resectable based on stage I-IIIA presentations, $4.3 \%$ were stage IIIB and the remainder were stage IV ( $n=9,39 \%)$. Unfortunately, stage IV disease was the most common single presenting stage. The majority of lung cancer originated in the lower lobes $(n=16,62 \%)$ and a similar number (64\%) were subpleural and within $2 \mathrm{~cm}$ of the pleural edge. Surgical resection was offered alone or in combination with chemotherapy or radiation in eight (31\%) patients. Overall mortality was $81 \%$, caused by the underlying primary cancer in $55 \%$, followed by infectious complications from treatment in 15\%. Figure 1 demonstrates Kaplan-Meier survival curves from the date of CPFE diagnosis stratified by those with and without lung cancer, noting decreased survival in those with lung cancer (log rank 0.0275). Median survival was 49 months (95\% CI 31-98 months) for those with lung cancer compared to 86 months (95\% CI 70-107 months) for those without. Eight CPFE patients without lung cancer underwent eventual lung transplantation.

Time to lung cancer diagnosis in those with CPFE-LC and yearly interval incidence of lung cancer for the whole cohort are presented in figure 2. Median time to lung cancer diagnosis was 31 months (95\% CI 17-45 months), ranging from half a month to 144 months after initial CPFE diagnosis.

Univariable and multivariable adjusted predictors of all-cause mortality for the whole CPFE study cohort using Cox proportional hazards regression analysis are presented in table 3. Independent predictors of death included age (unit hazard ratio (HR) 1.04, 95\% CI 1.02-1.06; $\mathrm{p}<0.0001$ ), use of supplemental home oxygen (HR 2.09, 95\% CI 1.24-3.51; p=0.005), RVSP (HR 1.02, 95\% CI 1.01-1.03; p<0.0001), $D_{\text {LCO }}$ (HR 0.98, 95\% CI 0.96-0.99; $\mathrm{p}=0.0011$ ), radiological honeycombing (HR 2.18, 95\% CI 1.49-3.19; $\mathrm{p}<0.001$ )

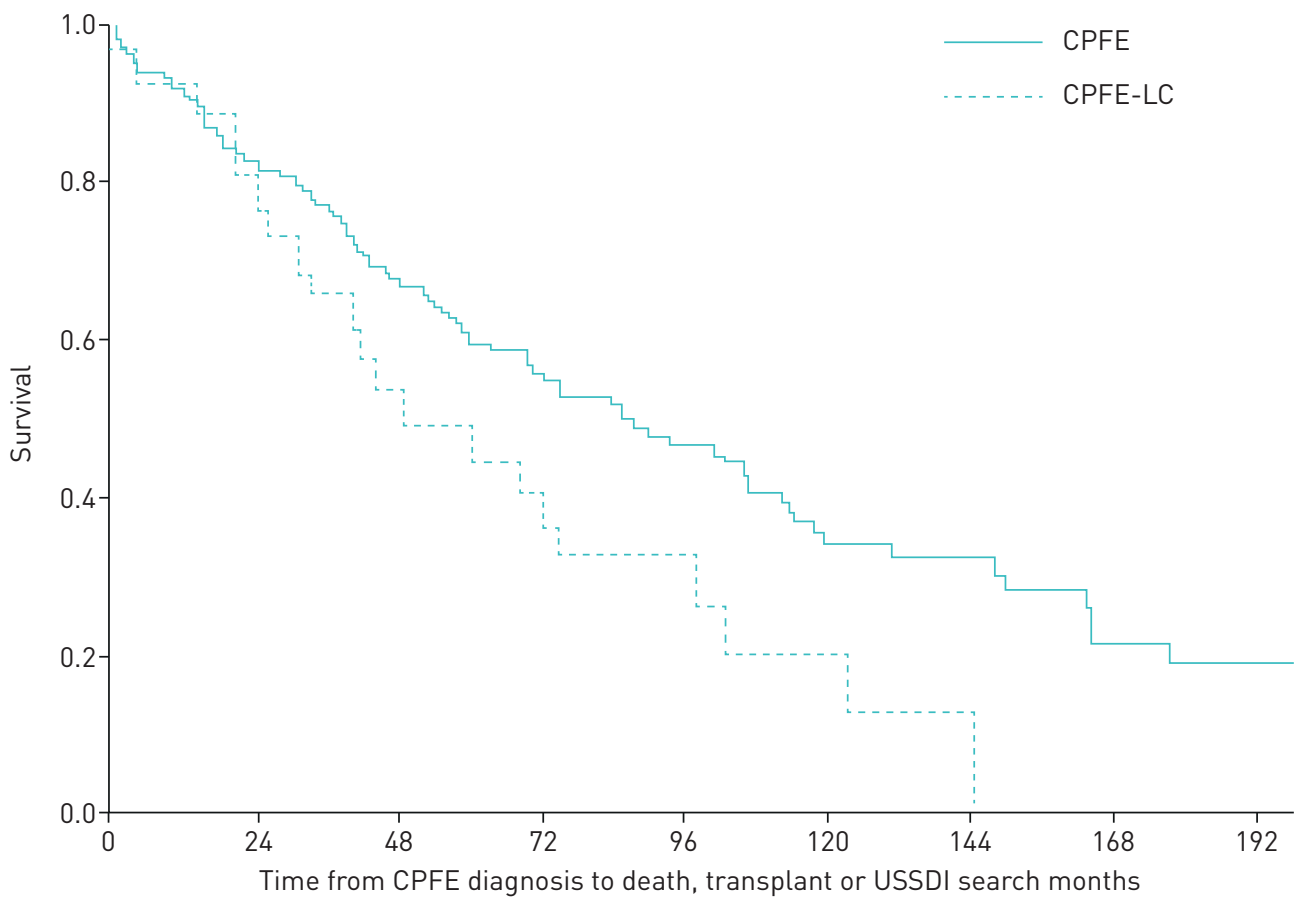

FIGURE 1 Kaplan-Meier analysis comparison of combined pulmonary fibrosis and emphysema (CPFE) with CPFE and lung cancer (CPFE-LC). Survival was poorer from the time of initial CPFE diagnosis for those with subsequent lung cancer (median survival 49 months, $95 \% \mathrm{Cl} 31-98$ months) compared to those without (median survival 86 months, 95\% Cl 70-107 months). Log rank 0.0275. USSDI: United States Social Security Death Index. 


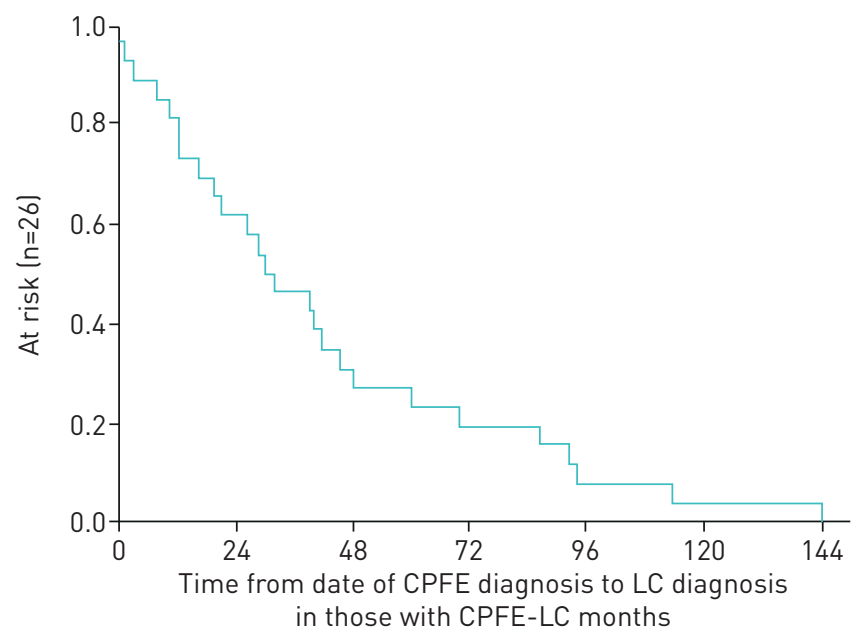

Interval risk for the whole cohort ( $n=230)$

\begin{tabular}{lcccccccccc}
\hline $\begin{array}{l}\text { Time } \\
\text { months }\end{array}$ & 0 & 12 & 24 & 36 & 48 & 72 & 84 & 96 & 120 & 144 \\
\hline $\begin{array}{l}\text { Interval } \\
\text { alive at } \\
\text { risk for LC }\end{array}$ & 230 & 210 & 179 & 136 & 107 & 66 & 55 & 44 & 25 & 17 \\
$\begin{array}{l}\text { Interval LC } \\
\text { cases }\end{array}$ & 0 & 5 & 5 & 4 & 5 & 2 & 0 & 3 & 1 & 1 \\
$\begin{array}{l}\text { Cumulative } \\
\text { LC cases }\end{array}$ & 0 & 5 & 10 & 14 & 19 & 21 & 21 & 24 & 25 & 26 \\
\hline
\end{tabular}

FIGURE 2 Kaplan-Meier time to lung cancer (LC) diagnosis. Median time to LC diagnosis was 31 months $195 \%$ Cl 17-45 months). Frequency of new LC diagnoses appeared greatest in the first 4 years of combined pulmonary fibrosis and emphysema (CPFE) diagnosis, based on interval risk for the whole cohort.

and lung cancer diagnosis (HR 2.25, 95\% CI 1.36-3.72; $\mathrm{p}=0.0015$ ). Among those subsequently diagnosed with lung cancer $(n=26)$, univariable predictors of mortality from the date of cancer diagnosis included the presence of radiological honeycombing (HR 3.03, 95\% CI 1.16-7.91; p=0.02), late or nonresectable cancer staging at presentation with the inclusion of small cell lung cancer (HR 4.77, 95\% CI 1.8-14.94 $\mathrm{p}=0.001$ ) and feasibility of surgical resection (HR 0.29, 0.09-0.87; $\mathrm{p}=0.02$ ) (table 4).

TABLE 3 Combined pulmonary fibrosis and emphysema (CPFE) univariable and multivariable Cox regression predictors of all-cause mortality for the whole cohort

\begin{tabular}{|c|c|c|c|c|}
\hline & $\begin{array}{l}\text { Univariable HR } \\
\text { (95\% CI) }\end{array}$ & p-value & $\begin{array}{c}\text { Multivariable }{ }^{\#} \text { HR } \\
\text { (95\% CI) }\end{array}$ & p-value \\
\hline $\begin{array}{l}\text { Age at CPFE diagnosis } \\
\text { years }\end{array}$ & $1.04(1.02-1.06)$ & $<0.0001$ & $1.04(1.02-1.06)$ & $<0.0001$ \\
\hline Male sex $\%$ & $1.25(0.83-1.90)$ & 0.28 & & \\
\hline Smoking pack-years ${ }^{\eta}$ & $1.00(0.99-1.01)$ & 0.22 & & \\
\hline Finger clubbing & $1.23(0.82-1.86)$ & 0.32 & & \\
\hline Home oxygen use & $1.98(1.21-3.28)$ & 0.004 & $2.09(1.24-3.51)$ & 0.005 \\
\hline RVSP $\mathrm{mmHg}$ & $1.02(1.01-1.03)$ & $<0.0001$ & $1.02(1.01-1.03)$ & $<0.0001$ \\
\hline FVC \% pred & $0.99(0.99-1.01)$ & 0.78 & & \\
\hline FEV $_{1} \%$ pred" & $0.99(0.99-1.01)$ & 0.89 & & \\
\hline$D_{\text {Lco }} \%$ pred $^{\text {T1 }}$ & $0.97(0.96-0.99)$ & $<0.0005$ & $0.98(0.96-0.99)$ & 0.0011 \\
\hline Presence of honeycombing & $2.07(1.44-2.97)$ & 0.0001 & $2.18(1.49-3.19)$ & $<0.001$ \\
\hline Lung cancer diagnosis & $1.69(1.05-2.71)$ & 0.039 & $2.25(1.36-3.72)$ & 0.0015 \\
\hline \multicolumn{5}{|c|}{$\begin{array}{l}\mathrm{n}=230 \text {. Bold type represents statistical significance. HR: hazard ratio; RVSP: right ventricular systolic } \\
\text { pressure; FVC: forced vital capacity; } \mathrm{FEV}_{1} \text { : forced expiratory volume in } 1 \mathrm{~s} ; D_{\mathrm{Lco}} \text { : diffusing capacity of the } \\
\text { lung for carbon monoxide. \#: adjusted for age, sex, pack-years, FVC } \% \text { pred and presence of } \\
\text { honeycombing; }{ }^{\natural} \text { : unit HRs for linear predictors. }\end{array}$} \\
\hline
\end{tabular}




\section{Discussion}

Our study of 230 patients represents the largest single-centre cohort to date of presenting CPFE patients meeting both clinical and radiological criteria set forward by CоттіN et al. [1] in 2005 followed over time for subsequent development of lung cancer. Prior studies have focused on large cohorts of already established lung cancer patients reviewed retrospectively for the presence of CPFE, leaving incident risk of lung cancer in CPFE previously unexplored in a systematic manner. Baseline functional and demographic characteristics of our CPFE cohort were similar to those described previously in terms of preserved lung volumes and normal range $\mathrm{FEV}_{1} \%$ pred [17-20]. Lung cancer diagnoses occurred in 26 (11.6\%) out of 230 CPFE patients, with squamous cell carcinoma being the most common histopathology. Disease staging at presentation was dominated by later presentation in the majority of cases (39\% stage IV). Age, subsequent diagnosis of lung cancer, use of supplemental oxygen and pulmonary hypertension were independent predictors of mortality after adjustment for a priori covariables. Honeycombing was the only unadjusted baseline predictor associated with worse survival among those with subsequent lung cancer. Successful surgical resection of earlier stage disease in our study was associated with improved outcome in likely highly selected patients.

Both emphysema and pulmonary fibrosis have been recognised as independent risk factors for the development of lung cancer. Radiological emphysema appears to be associated with idiopathic pulmonary fibrosis (IPF) in $\sim 30 \%$ of patients $[17,21]$. Data from the COPD Gene Study group suggests the presence of interstitial shadowing or radiologically overt interstitial pneumonia on CT in $\sim 5-10 \%$ of those with COPD [22, 23]. Increased incidence of lung cancer has been identified in large epidemiologic cohorts of pulmonary fibrosis, ranging between $4.4 \%$ and $4.9 \%$ of cases in the United Kingdom [24, 25] and $4.8 \%$ of cases from a review of incident deaths in the United States between 1979 and 1991 [26]. The incidence of lung cancer is $\sim 1 \%$ per year in those with COPD [27]. Lung cancer risk appears greater in CPFE (6.1-46.8\%) than in either IPF (4.4-4.9\%) or COPD alone [4, 7, 26, 28]. Lung cancer was diagnosed in $11.6 \%$ of our 230 CPFE cases, while three prior studies reviewing smaller sample sizes found new cases occurring in $25-47 \%$ of their respective cohorts $[4,12,13]$. Studies enrolling patients with diagnosed lung cancer as their primary study cohort also found significant incidence of associated CPFE [12], including some demonstrating greater frequency of lung cancer in CPFE than lone fibrosis $[6,29]$.

Squamous cell carcinoma and later stage disease were the primary features of CPFE-LC seen in our cohort. These findings are compatible with those of previous studies $[4,8,10,12,29,30]$. ZHANG et al. [6] reviewed the incidence of lung cancer in CPFE and non-CPFE resected patients, and found a greater incidence of squamous cell carcinoma with higher tumour grade than in those with fibrosis alone. In addition, they found disease extending more commonly from contiguous areas of histological fibrosis independent of tumour location. In our study, incident tumours had no laterality, but were dominated by a subpleural lower lobe distribution. Radiological honeycombing in our cohort occurred similarly in those

TABLE 4 Univariable Cox regression predictors of death in combined pulmonary fibrosis and emphysema (CPFE)-lung cancer patients

\begin{tabular}{|c|c|c|}
\hline & $\begin{array}{c}\text { Univariable HR } \\
\text { (95\% CI) }\end{array}$ & $\mathrm{p}$-value \\
\hline Age at cancer diagnosis years & $1.03(0.96-1.09)$ & 0.43 \\
\hline Male sex \% & $0.91(0.35-2.61)$ & 0.53 \\
\hline Smoking pack-years & $1.01(0.98-1.02)$ & 0.51 \\
\hline Finger clubbing & $1.15(0.40-2.86)$ & 0.78 \\
\hline Home oxygen use & $1.32(0.52-3.57)$ & 0.56 \\
\hline RVSP $\mathrm{mmHg}$ & $1.03(0.99-23.97)$ & 0.05 \\
\hline FVC \% pred & $0.98(0.95-1.01)$ & 0.16 \\
\hline FEV $_{1} \%$ pred & $0.99(0.97-1.02)$ & 0.39 \\
\hline$D_{\text {Lco }} \%$ pred & $0.97(0.93-1.00)$ & 0.14 \\
\hline Presence of honeycombing & $3.03(1.16-7.91)$ & 0.02 \\
\hline Adenocarcinoma versus others & $1.95(0.72-4.81)$ & 0.17 \\
\hline $\begin{array}{l}\text { Stage at presentation (late or nonresectable (stage III and IV, with } \\
\text { small cell) versus potentially resectable NSCLC (stages I and II)] }\end{array}$ & $4.77(1.8-14.94)$ & 0.001 \\
\hline Surgical resection performed & $0.29(0.09-0.87)$ & 0.02 \\
\hline
\end{tabular}


with and without lung cancer, and was an independent predictor of survival in both cohorts. KAWASAKI et al. [31] analysed the relationship between cancer location and regions of IPF, and reported that 50\% of new cancer diagnoses occurred in areas of fibrotic parenchyma. Such findings support the hypothesis that cancer development may be related to areas of fibrosis more than emphysema, explaining the radiological distribution of peripheral and lower lobe predominance as seen in our cohort and others. Zones of fibrosis and emphysema are often radiologically separated (upper lobe emphysema and lower lobe fibrosis) in typical CPFE, although overlap of histological findings at any one location cannot be excluded [2, 32]. Paraseptal emphysema has also been reported at the lung bases near fibrotic lesions, and may contribute to tumourigenesis $[2,33]$. In all, the development of lung cancer in patients with CPFE may be distinct from those with fibrosis or emphysema alone, although further research is needed to distinguish true areas of histological fibrotic change from emphysema as a determinant of tumour risk.

Lung cancer was associated with greater mortality in our CPFE cohort even after correction for a priori covariables. Additionally, we found that successful surgical resection of earlier stage disease in highly selected patients may improve outcomes despite concern for increased surgical risk. In contrast, MimAE and co-workers $[7,8]$ found that $\mathrm{CPFE}$ was associated with increased post-operative mortality and complications after lung resection, particularly among those with greater severity of radiological fibrosis. Presence of radiological honeycombing also appeared to contribute to poorer outcomes in those with lung cancer in our cohort. Honeycombing may confer a sense of more advanced fibrosis and deter surgical resection among those with potentially resectable disease, though in our limited dataset of diagnosed patients, frequency of radiological honeycombing did not differ among earlier or later stage disease. Falsely preserved $\mathrm{FEV}_{1}$ and FVC values and ratios in patients with CPFE may make lung volume assessment of pre-operative risk unreliable. Surgical risk appears associated with severity of radiological fibrosis [7] which may serve as a potential parameter for considering resection in those with earlier stage disease, although further research is needed. Lastly, pulmonary hypertension has also been reported previously as increasing surgical risk in those undergoing major lung resection, and may contribute to increased peri-operative morbidity [34]. RVSP in our study trended towards being predictive of mortality in those diagnosed with lung cancer, but was no different between those undergoing resection versus those who were eligible but did not receive it. Lung cancer staging appears to drive surgical resection more than suspicion for pulmonary hypertension, although this cannot be confirmed with this limited dataset.

In addition, we assessed contributing factors to overall survival among those with CPFE. Multivariable analysis revealed that age, elevated RVSP, home oxygen use, $D_{\mathrm{LCO}} \%$ pred and presence of radiological honeycombing were predictive of poorer outcome. KISHABA et al. [35] did not find FVC \% pred to be predictive of survival, while CHOI et al. did [3]. Finger clubbing has been described as a predictor of mortality in one prior study, while pulmonary hypertension has been well described as contributing to poorer survival among CPFE patients $[1,35]$. CPFE should be suspected in smokers with interstitial lung disease and preserved lung volumes but severely reduced $D_{\mathrm{LCO}}$. Recognition of radiological disease and closer monitoring of associated complications may allow for earlier detection of malignancy and opportunity for resection in the setting of other predictors of disease outcome. No recommendations currently exist regarding more specific or regular cancer screening in CPFE despite their apparent increased risk. Careful consideration should be given in weighing the potential benefit of earlier detection against related comorbidities and risk of surgical resection, where mortality as exemplified in our smaller study may be improved in carefully selected patients with earlier stage disease.

There are several limitations to our study. Despite a large sample size, a single-centre retrospective cohort can only assess correlation, but not causation. Selection bias may be present as not all eligible subjects had timed or serial radiographic and pulmonary function data available for analyses. Additionally, we only included patients with available CT for review. A smaller number of subsequently diagnosed CPFE-LC cases allowed for only univariable analysis, and cause of death was not known in $\sim 15 \%$ of the cohort. Despite these limitations, CPFE patients in our study were representative and characteristic of those reported in prior studies.

\section{Conclusion}

Lung cancer in CPFE was most commonly squamous cell carcinoma presenting in older male heavy smokers with a predominance of peripheral and lower lobe radiological presentations. Despite underlying fibrosis and emphysema, carefully selected earlier stage patients undergoing surgical resection still achieved mortality benefit. Weighing the risks of surgical resection after earlier detection with associated baseline comorbidities and other predictors of CPFE survival remain difficult. Further study is needed to understand factors associated with increased risk of lung cancer in CPFE, perhaps to determine a more disease-specific cancer screening programme for these patients. 


\section{References}

1 Cottin V, Nunes H, Brillet PY, et al. Combined pulmonary fibrosis and emphysema: a distinct underrecognised entity. Eur Respir J 2005; 26: 586-593.

2 Brillet PY, Cottin V, Letoumelin P, et al. Syndrome emphysème des sommets et fibrose pulmonaire des bases combinés (syndrome emphysème/fibrose): aspects tomodensitométriques et fonctionnels. [Combined apical emphysema and basal fibrosis syndrome (emphysema/fibrosis syndrome): CT imaging features and pulmonary function tests]. J Radiol 2009; 90: 43-51.

3 Choi SH, Lee HY, Lee KS, et al. The value of CT for disease detection and prognosis determination in combined pulmonary fibrosis and emphysema (CPFE). PLoS One 2014; 9: e107476.

4 Kwak N, Park CM, Lee J, et al. Lung cancer risk among patients with combined pulmonary fibrosis and emphysema. Respir Med 2014; 108: 524-530.

5 Koo HJ, Do KH, Lee JB, et al. Lung cancer in combined pulmonary fibrosis and emphysema: a systematic review and meta-analysis. PLoS One 2016; 11: e0161437.

6 Zhang M, Yoshizawa A, Kawakami S, et al. The histological characteristics and clinical outcomes of lung cancer in patients with combined pulmonary fibrosis and emphysema. Cancer Med 2016; 5: 2721-2730.

7 Mimae T, Suzuki K, Tsuboi M, et al. Severity of lung fibrosis affects early surgical outcomes of lung cancer among patients with combined pulmonary fibrosis and emphysema. Medicine 2016; 95: e4314.

8 Mimae T, Suzuki K, Tsuboi M, et al. Surgical outcomes of lung cancer in patients with combined pulmonary fibrosis and emphysema. Ann Surg Oncol 2015; 22: Suppl. 3, S1371-S1379.

9 Sato S, Koike T, Hashimoto T, et al. Surgical outcomes of lung cancer patients with combined pulmonary fibrosis and emphysema and those with idiopathic pulmonary fibrosis without emphysema. Ann Thorac Cardiovasc Surg 2016; 22: 216-223.

10 Otsuka H, Sugino K, Hata Y, et al. Clinical features and outcomes of patients with lung cancer as well as combined pulmonary fibrosis and emphysema. Mol Clin Oncol 2016; 5: 273-278.

11 Fukui M, Suzuki K, Matsunaga T, et al. Outcomes of lung cancer resection for patients with combined pulmonary fibrosis and emphysema. Surg Today 2016; 46: 341-347.

12 Kitaguchi Y, Fujimoto K, Hanaoka M, et al. Clinical characteristics of combined pulmonary fibrosis and emphysema. Respirology 2010; 15: 265-271.

13 Portillo K, Perez-Rodas N, García-Olivé I, et al. Lung cancer in patients with combined pulmonary fibrosis and emphysema and idiopathic pulmonary fibrosis. A descriptive study in a Spanish series. Arch Bronconeumol 2017; 53: $304-310$

14 Hansell DM, Bankier AA, MacMahon H, et al. Fleischner Society: glossary of terms for thoracic imaging. Radiology 2008; 246: 697-722.

15 Goldstraw P, Chansky K, Crowley J, et al. The IASLC Lung Cancer Staging Project: proposals for revision of the TNM stage groupings in the forthcoming (eighth) edition of the TNM classification for lung cancer. $J$ Thorac Oncol 2016; 11: 39-51.

16 Travis WD, Brambilla E, Muller-Hermelink HK, et al. Pathology and Genetics of Tumours of the Lung, Pleura, Thymus and Heart. World Health Organization Classification of Tumours. Lyon, IARC Press, 2004.

17 Mejía M, Carrillo G, Rojas-Serrano J, et al. Idiopathic pulmonary fibrosis and emphysema: decreased survival associated with severe pulmonary arterial hypertension. Chest 2009; 136: 10-15.

18 Akagi T, Matsumoto T, Harada T, et al. Coexistent emphysema delays the decrease of vital capacity in idiopathic pulmonary fibrosis. Respir Med 2009; 103: 1209-1215.

19 Jankowich MD, Rounds S. Combined pulmonary fibrosis and emphysema alters physiology but has similar mortality to pulmonary fibrosis without emphysema. Lung 2010; 188: 365-373.

20 Todd NW, Jeudy J, Lavania S, et al. Centrilobular emphysema combined with pulmonary fibrosis results in improved survival. Fibrogenesis Tissue Repair 2011; 4: 6.

21 Tasaka S, Mizoguchi K, Funatsu Y, et al. Cytokine profile of bronchoalveolar lavage fluid in patients with combined pulmonary fibrosis and emphysema. Respirology 2012; 17: 814-820.

22 Washko GR, Lynch DA, Matsuoka S, et al. Identification of early interstitial lung disease in smokers from the COPDGene Study. Acad Radiol 2010; 17: 48-53.

23 Washko GR, Hunninghake GM, Fernandez IE, et al. Lung volumes and emphysema in smokers with interstitial lung abnormalities. N Engl J Med 2011; 364: 897-906.

24 Hubbard R, Venn A, Lewis S, et al. Lung cancer and cryptogenic fibrosing alveolitis. A population-based cohort study. Am J Respir Crit Care Med 2000; 161: 5-8.

25 Le Jeune I, Gribbin J, West J, et al. The incidence of cancer in patients with idiopathic pulmonary fibrosis and sarcoidosis in the UK. Respir Med 2007; 101: 2534-2540.

26 Wells C, Mannino DM. Pulmonary fibrosis and lung cancer in the United States: analysis of the multiple cause of death mortality data, 1979 through 1991. South Med J 1996; 89: 505-510.

27 Sekine Y, Katsura H, Koh E, et al. Early detection of COPD is important for lung cancer surveillance. Eur Respir J 2012; 39: 1230-1240.

28 Congleton J, Muers MF. The incidence of airflow obstruction in bronchial carcinoma, its relation to breathlessness, and response to bronchodilator therapy. Respir Med 1995; 89: 291-296.

29 Usui K, Tanai C, Tanaka Y, et al. The prevalence of pulmonary fibrosis combined with emphysema in patients with lung cancer. Respirology 2011; 16: 326-331.

30 Girard N, Marchand-Adam S, Naccache JM, et al. Lung cancer in combined pulmonary fibrosis and emphysema: a series of 47 Western patients. J Thorac Oncol 2014; 9: 1162-1170.

31 Kawasaki H, Nagai K, Yoshida J, et al. Postoperative morbidity, mortality, and survival in lung cancer associated with idiopathic pulmonary fibrosis. J Surg Oncol 2002; 81: 33-37.

32 Rogliani P, Mura M, Mattia P, et al. HRCT and histopathological evaluation of fibrosis and tissue destruction in IPF associated with pulmonary emphysema. Respir Med 2008; 102: 1753-1761. 
33 Papaioannou AI, Kostikas K, Manali ED, et al. Combined pulmonary fibrosis and emphysema: the many aspects of a cohabitation contract. Respir Med 2016; 117: 14-26.

34 Wei B, D'Amico T, Samad Z, et al. The impact of pulmonary hypertension on morbidity and mortality following major lung resection. Eur J Cardiothorac Surg 2014; 45: 1028-1033.

35 Kishaba T, Shimaoka Y, Fukuyama H, et al. A cohort study of mortality predictors and characteristics of patients with combined pulmonary fibrosis and emphysema. BMJ Open 2012; 2: e000988. 